\title{
Preparation of Triacetoneamine, I
}

\author{
G. Sosnovsky and M. Konieczny \\ Department of Chemistry, University of Wisconsin-Milwaukee, \\ Milwaukee, Wisconsin 53201, USA \\ (Z. Naturforsch. 32 b, 328-337 [1977]; received November 29, 1976)
}

Triacetoneamine, Diacetoneamine, Mesityl Oxide, Acetonin, Diacetone Alcohol

The preparation of triacetoneamine (1) by the condensation of acetone with ammonia in the presence of calcium chloride at room temperature is investigated. In addition to $\mathbf{1}$, acetonin (3), diacetone alcohol (4), mesityl oxide, and diacetoneamine (7) are formed during the reaction. The progress of the reaction is monitored by gas chromatography. The effects of the extent and the rate of stirring, the amount of ammonia introduced on the critical first day of the reaction, and the mesh size and the amount of calcium chloride on the purity and weight yield of $\mathbf{1}$ are studied. The yield of $\mathbf{1}$ is maximized by recovery of the unreacted acetone. The reaction at room temperature under optimized conditions is described.

During the last 100 years, there have been intermittant reports on the preparation of 4-oxo-2,2,6,6tetramethylpiperidine, triacetoneamine $(\mathbf{1})$. It ap- pears that there are three main routes for the synthesis of this compound, i.e. from acetone ${ }^{1-10}$, from phorone ${ }^{11-13}(2)$, and from acetonin ${ }^{9,14,15}(3)$

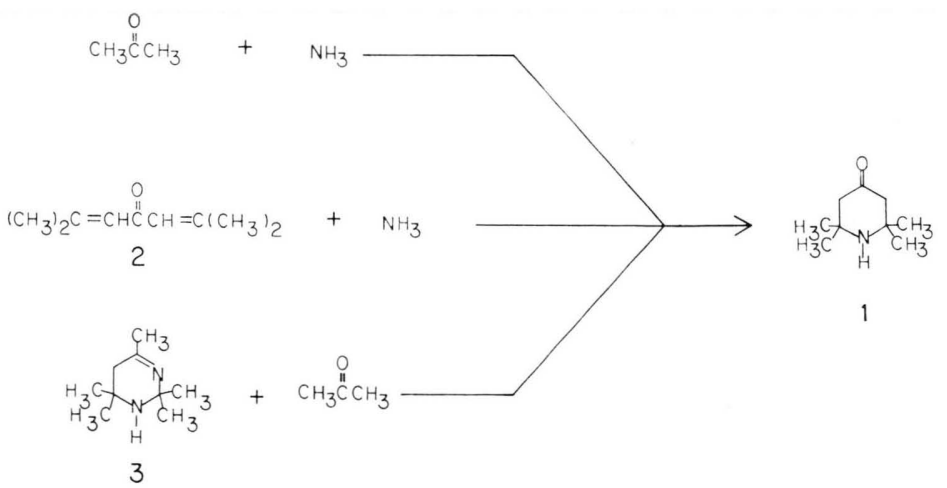

Another possible route to $\mathbf{1}$, though limited by the availability of the starting material, is the condensation ${ }^{9}$ of diacetone alcohol (4) with acetone and ammonia in the presence of calcium chloride.

$$
\underset{4}{\left(\mathrm{CH}_{3}\right)_{2} \mathrm{C}(\mathrm{OH}) \mathrm{CH}_{2} \mathrm{C}(\mathrm{O}) \mathrm{CH}_{3}}+\mathrm{NH}_{3} \rightarrow \mathbf{1}
$$

To the best of our knowledge, the earliest reports concerning 1 were published in 1874. Heintz ${ }^{1-3}$ and Sokoloff and LatschinofF ${ }^{4}$ independently discovered that on heating a solution of acetone

Requests for reprints should be sent to Prof. Dr. G. Sosnovsky, Department of Chemistry, University of Wisconsin-Milwaukee, Milwaukee, Wisconsin 53201 , USA. which had previously been saturated with ammonia, a basic material with the empirical formula of $\mathrm{C}_{9} \mathrm{H}_{17} \mathrm{NO}$ was produced. Sokoloff and LatSCHINOFF ${ }^{4}$ suggested the name triacetonehydramine, while Heintz ${ }^{1}$ proposed triacetoneamine for the new compound. It is the latter name which has been accepted into common usage by the chemical community.

It was not until 1894, that GUARESCHI ${ }^{11,12}$ established the structure $\mathbf{1}$ for triacetoneamine after preparing the compound in $71 \%$ yield by the reaction of phorone (2) and ammonia. At that time, it was also found that a stable monohydrate of $\mathbf{1}$ could be prepared. 
In 1927, Francis $^{5}$ reported the preparation of 1 by the condensation of acetone with ammonia in the presence of calcium chloride in $20-26 \%$ yield, calculated on the total acetone used, or

$$
\mathrm{CH}_{3} \mathrm{C}(\mathrm{O}) \mathrm{CH}_{3}+\mathrm{NH}_{3} \underset{-\mathrm{H}_{2} \mathrm{O}}{\longrightarrow} \mathrm{CaCl}
$$

$28 \%$ yield, taking into account the recovered unreacted acetone. Similar results were reported by $\mathrm{H}_{\mathrm{ALL}}{ }^{6} 30$ years later.

In 1968, AsINGer and coworkers ${ }^{7}$ described an elaborate apparatus for the production of triacetoneamine from acetone and ammonia in the presence of calcium chloride involving a process for the recovery of unreacted acetone. However, no better than a $40 \%$ yield of 1 was reported, taking into account the recovered acetone. A similarly complicated apparatus was proposed a few years later by Rozantsev and Ivanov ${ }^{8}$ for the preparation of $\mathbf{1}$ at elevated temperature. The authors recommended the apparatus for usage in pilot plant operations and semi-industrial installations, and, when properly operated, reportedly allowed for the production of 1 at a rate of approximately $150 \mathrm{~g}$ per day. In this process, unreacted acetone was recycled, and 1 was isolated from the reaction mixture by distillation. The yield of 1 was only $22 \%$, without taking into account the recovered acetone.

In 1975, Misharin and coworkers reported ${ }^{10 \mathrm{~b}}$ the preparation of 1 from acetone in the presence of calcium chloride, with ammonium carbonate presumably being used as the source of ammonia. However, the method is inconvenient since 20 days are needed for the reaction, and $\mathbf{1}$ is obtained in only a $25 \%$ yield. No attempts were made to recover unreacted acetone.

It had been reported ${ }^{16,17}$ that, under pressure, the reaction of acetone with ammonia in the presence of a mixture of calcium chloride and ammonium chloride produces 2,2,4,4,6-pentamethyl-2,3,4,5tetrahydropyrimidine, acetonin (3), in $82-88 \%$ yield.

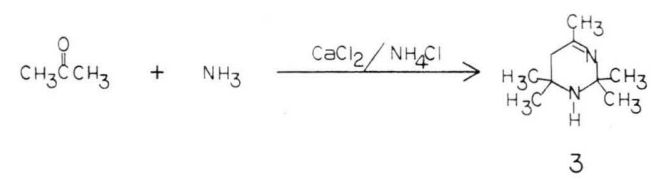

Recently, a considerable effort has been made by Murayama and coworkers 9,14 , to obviate the necessity of pressure and to optimize the yield of $\mathbf{3}$ by the use of various "promoters" such as bromine, ammonium thiocyanate, lithium nitrate, and other additives. Compound $\mathbf{3}$ was subsequently converted $^{9,15}$ to triacetoneamine (1) using additional amounts of acetone and various catalysts such as organic and mineral acids, primary, secondary, and tertiary amines, and various salts of these compounds. In most cases, the yield of 1 was above $90 \%$.

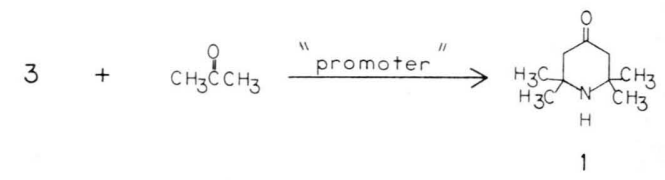

Each of the methods for the preparation of triacetoneamine (1) presented certain difficulties. The condensation of phorone (2) with ammonia gives a high yield of product, i.e. $71 \%$, but is severely limited by the difficulty in preparing and/or high cost of the starting material 2. Although the reaction of acetonin (3) with acetone produces $\mathbf{1}$ in high yields, and $\mathbf{3}$ in turn is also readily obtained from acetone and ammonia, the method involves a twostep reaction. An attempt ${ }^{9}$ was made to prepare 1 from diacetone alcohol (4) in order to utilize the byproduct of the triacetoneamine preparation. However, by this method, 1 was obtained in only moderate yield, i.e. $48 \%$, and thus this two-step method for the preparation of $\mathbf{1}$ might only be useful in the case where large quantities of $\mathbf{4}$ are readily available.

Since triacetoneamine (1) is the key intermediate in the preparation of 4-hydroxy-2,2,6,6-tetramethylpiperidine-1-oxyl (6),

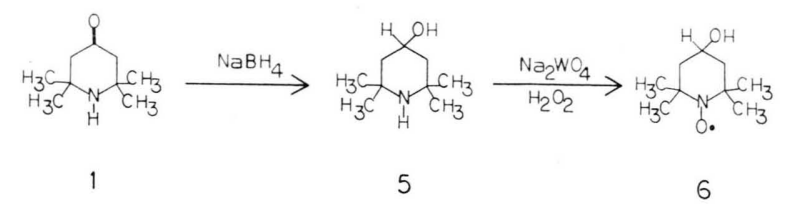

and we required large quantities of this material for the synthesis of spin-labelled phosphorus compounds containing the stable nitroxyl moiety, we found that the most convenient and least expensive method for the preparation of $\mathbf{1}$ was the one-step condensation of acetone with ammonia in the presence of calcium chloride. Since apparently no systematic study had been conducted concerning the effects of different variables on the yield and purity of $\mathbf{1}$ by this method, we decided to investigate this reaction in detail. 
Recently we briefly reported ${ }^{19}$ the improved preparation of $\mathbf{1}$. Now we wish to report in detail a study concerning the effects of the extent and rate of stirring, the amount and particle size of calcium chloride, the temperature during the reaction, duration of the reaction, amount of ammonia introduced, and addition of ammonium chloride on the yield and purity of $\mathbf{1}$. It was found that the reaction is extremely sensitive to some of these factors, while considerably less sensitive to others. The amount of $\mathbf{1}$ formed each day was monitored by gas chromatography. It was found that, even though ammonia was introduced during a three-day period, the amount of $\mathbf{1}$ present in the reaction mixture began to rise sharply only after the final introduction, i.e. on the fourth day (see experiment 1). This result is surprising, and indicates that the reaction proceeds at a slow rate. In order to explain the slow rate of formation of $\mathbf{1}$, it was assumed ${ }^{18}$ that, during the introduction of ammonia, a complex of the ammonia and calcium chloride is first formed which slowly releases the ammonia for the reaction with acetone. Although the reaction is a slow process, seven days appears to be a sufficient period of time for the completion of the reaction. Thus, when the reaction time was extended to 14 days, no appreciable increase in either the yield or the purity of 1 was observed (see experiment 2). A typical gas chromatographic analysis of a crude mixture resulting from a reaction performed under the optimized conditions, just prior to the distillation or solidification from carbon tetrachloride (see experiment 1), is shown in Fig. 1.

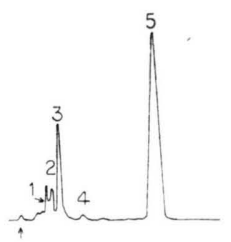

Fig. 1. Gas chromatographic analysis of the crude product obtained from the reaction performed under optimized conditions. Arrow indicates injection of sample. 1) Mesityl oxide. 2) Diacetoneamine (7). 3) Acetonin (3). 4) Diacetone alcohol (4). 5) Triacetoneamine (1).

In addition to triacetoneamine (1), the crude reaction mixture contains mesityl oxide, diacetoneamine (7), acetonin (3),

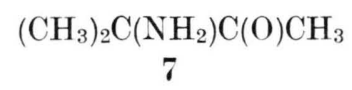

and diacetone alcohol (4). These impurities comprise approximately $15 \%$ by weight of the crude reaction mixture. Since 1 can be prepared from phorone (2) and ammonia, and phorone itself is formed by a condensation of acetone, compound 2 might be assumed as the intermediate in the preparation of $\mathbf{1}$ from acetone and ammonia in the presence of calcium chloride. However, no trace of $\mathbf{2}$ was ever detected in our analyses by gas chromatography. It is possible that either the reaction of acetone with ammonia to produce $\mathbf{1}$ does not proceed through $\mathbf{2}$ as the intermediate, or that any $\mathbf{2}$, as it is formed, instantaneously condenses with ammonia to give $\mathbf{1}$ and, thus, is never detected.

The extent of stirring during the three days of the introduction of ammonia affects the yield of $\mathbf{1}$ to some extent. Thus, in the case that the reaction mixture was stirred at about $300 \mathrm{rpm}$ only during the introduction of ammonia, a $43 \%$ yield, taking into account the recovered acetone, of 1 was obtained, whereas the yield was raised to $70 \%$ if stirring was maintained continuously during all three days of the introduction of ammonia. A reduction of the stirring rate by a factor of two to about $150 \mathrm{rpm}$ reduced the weight yield of 1 also by nearly a factor of two (see experiment 4), while the yield, based on the reacted acetone, was $41 \%$. An increase of the stirring rate to about $500 \mathrm{rpm}$ did not appreciably affect the yield of 1 .

The mesh size of calcium chloride can play a key role in the success or failure of the reaction, particularly on the critical first day. The appearance of the reaction mixture during the three days of introduction of ammonia is a very good indicator of the quality of 1 to be expected (see experiments 1 and 6). If a calcium chloride of either 4-8 mesh or 4-20 mesh was used, no more than 1.5-2.0 mols of ammonia could be added on the first day. As the ammonia was introduced, the heterogeneous reaction mixture became progressively more and more homogeneous, i.e. the calcium chloride granules were reduced to a powder-like consistency. After approximately 2.0 moles of the ammonia had been introduced, the reaction mixture suddenly reverted to heterogeneity. If the introduction of ammonia was immediately stopped, and the mixture was stirred for 20 hours at room temperature, homogeneity was once again attained. On the second day, the cream-colored reaction mixture would thicken slightly during the introduction of ammonia, 
become more fluid once again during the 20 hours of subsequent stirring, and then thicken appreciably during the third day's introduction, without ever losing its homogeneity. During the following four days when the reaction mixture was left undisturbed at room temperature, it slowly separated to some extent into two layers of a viscous red-brown oil and a yellow sediment. The calcium chloride at the end of the reaction was in a form different to that observed at the beginning of the reaction. In fact, after the first introduction of ammonia, no granules of the original size of calcium chloride were ever again observed. However, if an attempt was made to continue the introduction of ammonia on the first day, even though heterogeneity was obtained, beyond $2.0 \mathrm{~mol}$ of ammonia, the purity of 1 would be markedly reduced from the $85 \%$ under optimized conditions, to $42 \%$ (see experiment 6 ). In this case, the reaction mixture became homogeneous during the 20 hours of stirring between the first and second introduction of ammonia, but the thickening which occurred during the optimized reaction was never observed. In this case, towards the end of the third and last day's introduction, the reaction mixture suddenly reverted back to a heterogeneous mixture containing calcium chloride granules of approximately 4-20 mesh size and a non-viscous red-orange liquid. The purity of triacetoneamine (1) in such a case was reduced drastically to $42 \%$, even though 2.5 mols rather than the recommended 2.0 mols of ammonia were introduced on the first day. The main contaminant was acetonin (3), comprising as much as $50 \%$ of the total impurities. The observed amounts of other impurities, such as, diacetone alcohol (4) and diacetoneamine (7) increased slightly, but not to the extent of acetonin (3). A typical gas chromatographic analysis of the crude product mixture resulting from such an experiment is shown in Fig. 2.

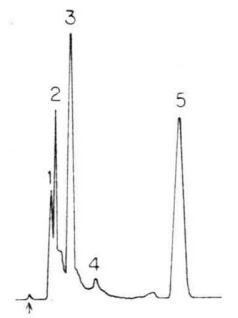

Fig. 2. Gas chromatographic analysis of the crude product obtained from the reaction during which $2.5 \mathrm{~mol}$ ammonia was introduced on the first day. Arrow indicates injection of sample. 1) Mesityl oxide.

2) Diacetoneamine (7). 3) Acetonin (3). 4) Diacetone alcohol (4). 5) Triacetoneamine (1).
In the case that a powdered calcium chloride of 20 mesh size or finer was used in the reaction, as much as 3.5 mols of ammonia could be introduced on the first day without adversely affecting the purity of 1 . However, since the reaction mixture consisted of extremely finely divided particles throughout all seven days of the reaction, care had to be exercised to insure good stirring at a rate of at least $300 \mathrm{rpm}$.

The amount of calcium chloride is an important factor influencing the purity of 1 . The optimum amount appears to be about 400 grams. If 500 grams were used, the yield of product 1 decreased while the purity was not adversely affected, although the mixture was difficult to stir due to the high viscosity. Furthermore, the extra amount of calcium chloride seemed to trap some of the acetone, and as a result, only $38 \%$ of the unreacted acetone could be detected by gas chromatography. Only after the reaction mixture was poured into an aqueous sodium hydroxide solution was the remaining acetone released (see experiment 8 ). In those cases where less than 400 grams of calcium chloride was used, the purity of $\mathbf{1}$ decreased sharply. Thus, with 350 grams of calcium chloride was the effect already noted, since the purity in this case decreased from $85 \%$ to $69 \%$. The appearance of each reaction mixture with less than 400 grams of calcium chloride was similar to that with an "overkill" of ammonia on the first day. The main impurity in each reaction was acetonin (3). The smaller the amount of calcium chloride, the greater was the percentage of $\mathbf{3}$ formed as a by-product. The results of these experiments are listed in Table I.

Table I. The effect of the amount of calcium chloride per $1000 \mathrm{~g}$ of acetone on the purity of $\mathbf{1}$.

\begin{tabular}{lllll}
\hline $\begin{array}{l}\text { Amount } \\
\text { of } \mathrm{CaCl}_{2} \\
{[\mathrm{~g}]^{\mathrm{a}}}\end{array}$ & $\begin{array}{l}\text { Purity } \\
\text { of 1 } \\
{[\%]^{\mathrm{b}}}\end{array}$ & $\begin{array}{l}\text { 3 in total } \\
\text { impurities } \\
{[\%]^{\mathrm{b}}}\end{array}$ & $\begin{array}{l}\text { Yield } \\
\text { of 1 } \\
{[\%]^{\mathrm{c}}}\end{array}$ & $\begin{array}{l}\text { Yield } \\
\text { of 3 } \\
{[\%]^{\mathrm{b}}}\end{array}$ \\
\hline 500 & 86 & 30 & 30 & 4 \\
$400^{\mathrm{d}}$ & 85 & 30 & 48 & 4 \\
350 & 69 & 45 & 28 & 14 \\
300 & 59 & 50 & 26 & 20 \\
250 & 48 & 52 & 19 & 27 \\
215 & 36 & 52 & 17 & 33 \\
128 & 35 & 59 & 13 & 38 \\
\hline
\end{tabular}

a Per $1000 \mathrm{~g}$ of acetone. $\mathrm{b}$ As determined by gas chromatography. ${ }^{\mathrm{c}}$ As obtained by distillation, without taking into account the unreacted acetone. d Optimized reaction (experiment 1 ). 
The preferred method of purification of crude triacetoneamine (1) obtained at room temperature, regardless of the purity, was by distillation. As can be seen from experiment 1 , a yield of $70 \%$ of 1 was obtained by distillation, after taking into account the recovered unreacted acetone. This yield was reduced to $34 \%$ if 1 was isolated by solidification of the crude 1 using carbon tetrachloride, and as much as $50 \%$ of unrecoverable 1 remained in the mother liquor, as determined by gas chromatography. Furthermore, it was difficult to remove the last traces of the solvent from the product after the crystallization. In addition, there is a critical level of purity of the crude $\mathbf{1}$ which must be attained if $\mathbf{1}$ is to be isolated by solidification from carbon tetrachloride. Thus, if the purity of the crude triacetoneamine (1) falls below $70-75 \%$, distillation is the sole method for isolation of the pure compound $\mathbf{1}$, although in such cases, due to the high vapor pressure of the by-products, i.e. acetonin (3), diacetone alcohol (4), diacetoneamine (7), and mesityl oxide, the separation of these compounds from triacetoneamine (1) was difficult.

\section{Experimental}

Materials: All reagents were of the best quality commercially available. The calcium chloride of 4-8 mesh and 4-20 mesh was obtained from Fisher Scientific Company. The powdered calcium chloride of 20 or finer mesh was obtained from the J. T. Baker Chemical Company. Mesityl oxide, phorone (2), and diacetone alcohol (4) were obtained commercially. Diacetoneamine (7) was prepared as described in literature ${ }^{21}$ and isolated as its oxalate. The free amine was liberated into ether with sodium hydroxide. This ethereal solution was used in gas chromatographic analyses. Acetonin (3) was prepared $^{14}$ by way of the condensation of acetone with ammonia in the presence of ammonium thiocyanate, and was isolated in $91 \%$ purity from a reaction mixture by distillation (see experiment 12). Triacetoneamine (1) was reduced to 4 -hydroxy-2,2,6,6tetramethylpiperidine (5) with sodium borohydride 19,20 .

The reaction was performed in a 3 -liter 4-neck round bottom flask equipped with a thermometer, a reflux condenser with a drying tube, and a powerful overhead stirrer, and a gas inlet tube. The reaction mixture was stirred at a rate of $300 \mathrm{rpm}$ unless otherwise indicated. The anhydrous ammonia was introduced from a lecture bottle. Thus the precise amount of gas added each time could be determined by difference in weight. The speed of the overhead stirrer was measured on full load periodically during the course of the reaction by means of a tachometer. The rate of stirring did not vary by more than $10 \%$ during this time.

Analytical procedures: All melting points and boiling points are uncorrected. Microanalyses were performed on a F \& M Scientific Corporation Carbon, Hydrogen, Nitrogen Analyzer, Model 185. An Aerograph A 90-P3 gas chromatograph with a thermal conductivity detector was used. The following overall conditions were maintained: injector temperature, $225{ }^{\circ} \mathrm{C}$; detector temperature, $250^{\circ} \mathrm{C}$; bridge current, $150 \mathrm{ma}$; sample size, $5 \mu \mathrm{l}$ with the appropriate attentuations. The column used was $20 \%$ Carbowax $20 \mathrm{M}$ on $60 / 80 \mathrm{mesh}$ acid washed Chromasorb W, $6 \mathrm{ft}$ by $1 / 4$ in. Analyses were performed isothermally at $170^{\circ} \mathrm{C}$, with a flow rate of $60-65 \mathrm{ml}$ of $\mathrm{He} / \mathrm{min}$. All identifications of products were made by the comparison of retention times and peak enhancement ("spiking") with authentic samples.

\section{Preparation of acetonin (3)}

The present procedure is a modification of the one reported in literature ${ }^{14}$. To a well-stirred mixture of reagent grade acetone $(60.0 \mathrm{~g}, 1.08 \mathrm{~mol})$ and $\mathrm{am}$ monium thiocyanate $(0.33 \mathrm{~g}, 0.0044 \mathrm{~mol}, 0.4 \mathrm{~mol} \%$ of acetone) was slowly introduced at $25-30{ }^{\circ} \mathrm{C}$ during $3 \mathrm{~h}$ anhydrous ammonia $(17.6 \mathrm{~g}, 1.03 \mathrm{~mol})$. After the addition, the colorless homogeneous reaction mixture was stirred at ambient temperature for $1 \mathrm{~h}$, then treated with $30 \mathrm{ml}$ of $48 \%$ aqueous sodium hydroxide. The aqueous layer was separated, and the organic layer stored at $-20^{\circ} \mathrm{C}$ for $20 \mathrm{~h}$. During this time, the crude product solidified. On warming to room temperature, the solid reverted to a semisolid material. The crude mixture was dried on a porcelain plate. Thus was collected $48 \mathrm{~g}$ $(78 \%)$ of 3 as the hydrate, m.p. $42-43{ }^{\circ} \mathrm{C}$; lit. ${ }^{16,17}$ m.p. $43^{\circ} \mathrm{C}$.

\section{Calcd C 62.75 H $11.70 \quad$ N 16.26, \\ Found C 62.74 H $11.46 \quad \mathrm{~N} 16.39$.}

\section{Preparation of triacetoneamine (1)}

\section{Reaction at room temperature under optimized conditions}

General procedure A: Anhydrous ammonia $(34.0 \mathrm{~g}$, $2.0 \mathrm{~mol}$ ) was introduced to a well-stirred mixture of reagent grade acetone $(1000 \mathrm{~g}, 17.3 \mathrm{~mol})$ and anhydrous calcium chloride (400 g, 4-20 mesh size) at room temperature. The reaction mixture was stirred for $20 \mathrm{~h}$, then, on the second day, anhydrous ammonia $(32.0 \mathrm{~g}, 1.9 \mathrm{~mol})$ was again introduced. The reaction mixture was stirred at room temperature for $3 \mathrm{~h}$, then treated with anhydrous ammonia $(25.0 \mathrm{~g}, 1.5 \mathrm{~mol})$. On the third day, following $16 \mathrm{~h}$ of stirring, anhydrous ammonia $(20.0 \mathrm{~g}, 1.2 \mathrm{~mol})$ was introduced. The reaction mixture was stirred for $4 \mathrm{~h}$, then treated with anhydrous ammonia $(29.0 \mathrm{~g}, 1.7 \mathrm{~mol})$. During the period of introduction, the temperature of the reaction mixture was not allowed to exceed $46{ }^{\circ} \mathrm{C}$. After the last introduction, 
stirring was discontinued, and the thickened reaction mixture was left undisturbed at $23-25^{\circ} \mathrm{C}$ for 4 days. The approximate amount of triacetoneamine (1) formed each day of the seven day reaction period was monitored by gas chromatography. Then, the apparatus was converted for distillation, and the reaction mixture stirred at $35^{\circ} \mathrm{C}$ under reduced pressure (100 torr). The unreacted acetone was collected in two traps chilled by isopropyl alcohol/ dry ice baths. All precautions were taken to exclude moisture from the system. In this manner were collected $310 \mathrm{~g}(31 \%$ based on moles initially used) of acetone. To the remaining cake was added $500 \mathrm{ml}$ of an aqueous solution containing $100 \mathrm{~g}$ sodium hydroxide. The mixture was vigorously stirred. The oil was decanted. The remaining aqueous slurry was extracted with diethyl ether $(5 \times 200 \mathrm{ml})$. The combined oil and ethereal extracts were dried over anhydrous magnesium sulfate. The drying agent was removed by filtration. Removal of the solvent on a rotating evaporator at $25^{\circ} \mathrm{C}(12-15$ torr) gave $644 \mathrm{~g}$ of crude 1 . The purity of 1 , as determined by gas chromatography, was $85 \%$. Unreacted acetone, as determined by gas chromatography, plus that converted to 1 was accountable to $97 \%$. Unreacted acetone $(310 \mathrm{~g}, 31 \%$ of the total acetone used) recovered by distillation plus that converted to 1 was accountable to $92 \%$. Distillation of the crude reaction mixture under reduced pressure afforded $430 \mathrm{~g}(48 \%$ yield based on starting acetone, or $70 \%$ yield taking into account the recovered acetone) of 1 , b.p. $50-56{ }^{\circ} \mathrm{C}$ (1 torr), m.p. $35-36{ }^{\circ} \mathrm{C}$. Lit. ${ }^{5,6}$ $\mathrm{m} . \mathrm{p} .34-36{ }^{\circ} \mathrm{C}$. The purity of 1 , as determined by gas chromatography was $97 \%$. Pure 1 was also obtained by solidification in carbon tetrachloride. Thus, $644 \mathrm{~g}$ of crude 1 of $85 \%$ purity was mixed with an equal volume of carbon tetrachloride and stored at $0^{\circ} \mathrm{C}$ overnight. The solid was collected by filtration, and kept at room temperature at 10-12 torr until all traces of solvent were removed. Thus was obtained $210 \mathrm{~g}$ ( $24 \%$ yield based on starting acetone, or $34 \%$ yield taking into account the recovered acetone) of $1, \mathrm{~m}$.p. $34-36{ }^{\circ} \mathrm{C}$. The additional details of this experiment, including the amount of $\mathbf{1}$ formed each day and the appearance of the reaction mixture follow.

\begin{tabular}{|c|c|c|c|c|c|}
\hline Day & $\begin{array}{l}\text { Ammonia introduced } \\
\text { per day } \\
\mathrm{g}[\mathrm{mols}]\end{array}$ & $\begin{array}{l}\text { Total ammonia } \\
\text { in reaction mixture } \\
{[\%]}\end{array}$ & $\begin{array}{l}\text { Duration of } \\
\text { introduction } \\
{[\mathrm{min}]}\end{array}$ & $\begin{array}{l}\text { Temperature } \\
\text { during introduction } \\
{\left[{ }^{\circ} \mathrm{C}\right]}\end{array}$ & $\begin{array}{l}\mathbf{1} \\
\text { Present } \\
{[\%]}\end{array}$ \\
\hline $1^{\mathrm{a}}$ & $34(2.0)$ & 24 & 30 & $30-36$ & $0^{\mathrm{d}}$ \\
\hline $2^{\mathrm{b}}$ & $57(3.4)$ & 65 & 45 & $23-46$ & $1^{\mathrm{e}}$ \\
\hline $3^{c}$ & $49(2.9)$ & $100(8.3 \mathrm{~mol})$ & 45 & $23-39$ & 5 \\
\hline 4 & & & & & 9 \\
\hline 5 & & & & & 30 \\
\hline 6 & & & & & 36 \\
\hline 7 & & & & & 40 \\
\hline 8 & & & & & $48^{\mathrm{f}}$ \\
\hline
\end{tabular}

a A heterogeneous mixture of a white solid and colorless liquid resulted after the introduction of ammonia. The mixture became homogeneous overnight. b The yellow mixture thickened slightly during the second day's introduction. " The mixture thickened considerably during the third day's introduction and remained nearly homogeneous and very thick during the remaining five days. During this time, a small amount of a dark orange oil separated. d The analyses for $\mathbf{1}$ in the reaction mixture were always performed by gas chromatography approximately $24 \mathrm{~h}$ after the previous day's introduction of ammonia, i.e. just prior to the next day's introduction. e The values are an average of five experiments. ${ }^{\mathrm{f}}$ The yield was based on $\mathbf{1}$ obtained after distillation of the crude product without taking into account the acetone recovered by distillation. The yield was $70 \%$, taking into account this recovered acetone.

\section{Reaction at room temperature over a period of 14 days}

General procedure B: Anhydrous ammonia (137.0g, $8.0 \mathrm{~mol}$ ) was introduced at room temperature in four portions over a period of four days to a wellstirred mixture of reagent grade acetone $(1000 \mathrm{~g}$, $17.3 \mathrm{~mol}$ ) and anhydrous calcium chloride (400 g, 4-8 mesh size). After the final introduction, stirring was discontinued, and the reaction mixture was left undisturbed for an additional 11 days. The thickened reaction mixture was poured into $500 \mathrm{ml}$ of an aqueous solution containing $100 \mathrm{~g}$ sodium hydroxide. The mixture was stirred until an oil separated. The oil was decanted and the remaining caustic slurry washed with diethyl ether $(5 \times 200 \mathrm{ml})$. The combined oil and ethereal extracts were dried over anhydrous magnesium sulfate. The drying agent was removed by filtration and the filtrate was concentrated on a rotating evaporator at $20-22{ }^{\circ} \mathrm{C}$ (12-15 torr) to give $598 \mathrm{~g}$ of crude 1 . The purity of 1 , as determined by gas chromatography, was $75 \%$. Unreacted acetone, determined by gas chromatography, plus that converted to $\mathbf{1}$ and to the byproducts was accountable to $89 \%$. Solidification of the crude reaction mixture in carbon tetrachloride afforded $295 \mathrm{~g}(33 \%$ yield based on total acetone, or $47 \%$ yield taking into account the acetone as determined by gas chromatography) of 1, m.p. $34-36{ }^{\circ} \mathrm{C}$. 


\section{Reaction at room temperature with stirring only} during the introduction of ammonia

Anhydrous ammonia $(34.0 \mathrm{~g}, 2.0 \mathrm{~mol})$ was introduced at room temperature to a well-stirred mixture of reagent grade acetone $(1000 \mathrm{~g}, 17.3 \mathrm{~mol})$ and anhydrous calcium chloride (400 g, 4-8 mesh size). Following the introduction, the reaction mixture was stirred for $24 \mathrm{~h}$, treated with anhydrous ammonia $(38.0 \mathrm{~g}, 2.2 \mathrm{~mol})$, and left undisturbed for $24 \mathrm{~h}$. Stirring was then resumed. The final amount of anhydrous ammonia (65.0 g, $3.8 \mathrm{~mol}$ ) was introduced, and the reaction mixture left undisturbed for four days. After the workup as described in the general procedure $\mathrm{B}$, there was obtained $555 \mathrm{~g}$ of crude 1 of $76 \%$ purity, as determined by gas chromatography. Unreacted acetone, determined by gas chromatography, plus that converted to $\mathbf{1}$ and by-products was accountable to $97 \%$. The crude 1 was allowed to solidify in carbon tetrachloride. After removal of all traces of solvent at room temperature at $12-15$ torr there was obtained $200 \mathrm{~g}$ $(22 \%$ yield based on starting acetone, or $35 \%$ yield taking into account the acetone, as determined by gas chromatography) of $1, \mathrm{~m} . \mathrm{p} .34-36{ }^{\circ} \mathrm{C}$.

\section{Reaction at room temperature with a stirring rate of about $150 \mathrm{rpm}$}

Anhydrous ammonia (141.0 g, $8.3 \mathrm{~mol}$ ) was introduced at room temperature in four portions over a period of four days to a well-stirred mixture of reagent grade acetone $(1000 \mathrm{~g}, 17.3 \mathrm{~mol})$ and anhydrous calcium chloride (400 g, 4-8 mesh size) stirred at $120-165 \mathrm{rpm}$. After the final introduction, the thickened reaction mixture was left undisturbed for an additional 3 days. After the workup as described in the general procedure $\mathrm{A}$, there was obtained $324 \mathrm{~g}$ of crude 1 . The purity of $\mathbf{1}$, as determined by gas chromatography, was $84 \%$. Unreacted acetone, as determined by gas chromatography, plus that reacted to $\mathbf{1}$ and by-products was accountable to $99 \%$. Unreacted acetone, recovered by distillation (536 g, 54\% of total acetone used) plus that converted to $\mathbf{1}$ and by-products was accountable to $86 \%$. The crude 1 was solidified in carbon tetrachloride to give $160 \mathrm{~g}$ ( $18 \%$ yield based on total acetone, or $40 \%$ yield taking into account the acetone recovered by distillation) of $1, \mathrm{~m} . \mathrm{p}$. $34-36{ }^{\circ} \mathrm{C}$.

\section{Reaction at room temperature with a stirring rate of about $500 \mathrm{rpm}$}

Anhydrous ammonia (143.0 g, $8.4 \mathrm{~mol}$ ) was introduced at room temperature in four portions over a period of four days to a mixture of reagent grade acetone $(1000 \mathrm{~g}, 17.3 \mathrm{~mol})$ and anhydrous calcium chloride (400 g, 4-8 mesh size) stirred at 510-550 rpm. The reaction mixture never attained the very thick consistency of the more slowly stirred mixture. After the fourth introduction, stirring was discontinued and the reaction mixture was left undisturbed for three days. Following the workup as described in the general procedure $\mathrm{B}$, there was obtained $555 \mathrm{~g}$ of crude 1 . The purity of 1 , as determined by gas chromatography, was $82 \%$. The acetone, as determined by gas chromatography, plus that converted to 1 and by-products was accountable to $97 \%$. Distillation of the crude material afforded $385 \mathrm{~g}$ $(43 \%$ yield based on total acetone, or $62 \%$ yield taking into account the acetone, as determined by gas chromatography) of 1 , b.p. $50-57^{\circ} \mathrm{C}$ (1 torr), m.p. $33-36{ }^{\circ} \mathrm{C}$.

\section{Reaction at room temperature with 2.5 mols of ammonia introduced on the first day}

Anhydrous ammonia $(42.0 \mathrm{~g}, 2.5 \mathrm{~mol})$ was introduced at room temperature to a well-stirred mixture of reagent grade acetone $(1000 \mathrm{~g}, 17.3 \mathrm{~mol})$ and anhydrous calcium chloride ( $400 \mathrm{~g}, 4-8$ mesh size). A heterogeneous reaction mixture resulted. The reaction mixture was stirred for $20 \mathrm{~h}$. The remaining anhydrous ammonia $(98.0 \mathrm{~g}, 5.7 \mathrm{~mol})$ was then introduced on the second and third day in four approximately equal portions. A heterogeneous reaction mixture resulted during the final day's introduction. Stirring was discontinued, and the redcolored heterogeneous reaction mixture was left undisturbed for three days. After the workup, as described in the general procedure $\mathrm{B}$, there was obtained $452 \mathrm{~g}$ of crude 1 . The purity of 1 , as determined by gas chromatography, was $42 \%$. The major impurity comprising $48 \%$ of the by-products was acetonin (3). Unreacted acetone as identified by gas chromatography plus that converted to $\mathbf{1}$ and by-products was accountable to $97 \%$. The material was of such inferior quality that no crystallization of solid 1 could be achieved from carbon tetrachloride. Distillation of the crude material afforded $136 \mathrm{~g}$ (15\% yield based on total acetone, or $30 \%$ yield taking into account the acetone, as determined by gas chromatography) of $\mathbf{1}$, b. p. $50-57^{\circ} \mathrm{C}$ (1 torr), m.p. $34-35^{\circ} \mathrm{C}$.

\section{Reaction at room temperature using powdered calcium chloride}

A mixture of reagent grade acetone $(1000 \mathrm{~g}$, $17.3 \mathrm{~mol}$ ) and powdered anhydrous calcium chloride (400 g, 20 mesh size or finer) was stirred for $4 \mathrm{~h}$. During this time, the reaction mixture became homogeneous, very thick, and highly exothermic causing the acetone to boil. After the mixture had cooled down to room temperature $\left(23^{\circ} \mathrm{C}\right)$, anhydrous ammonia (140.0 g, $8.2 \mathrm{~mol}$ ) was introduced in four portions over a period of three days. Due to the fine particle size of the calcium chloride, more than $2.0 \mathrm{~mol}$ ammonia could be introduced on the first day without attaining heterogeneity. After the final introduction of ammonia, stirring was discontinued, and the reaction mixture was left undisturbed for four days. After work-up as described in the general procedure $\mathrm{A}$, there was obtained $625 \mathrm{~g}$ of crude 1 . The purity of $\mathbf{1}$, as determined by gas chromatography was $77 \%$. Unreacted acetone, as determined 
by gas chromatography, plus that converted to $\mathbf{1}$ and all by-products was accountable to $99 \%$. Unreacted acetone, recovered by distillation $(250 \mathrm{~g}$, $25 \%$ of the total acetone used) plus that converted to 1 and all by-products was accountable to $79 \%$. The crude reaction mixture was solidified in carbon tetrachloride to give $305 \mathrm{~g}$ ( $34 \%$ yield based on total acetone used, or $46 \%$ yield taking into account the acetone recovered by distillation) of $1, \mathrm{~m} . \mathrm{p}$. 34-36 ${ }^{\circ} \mathrm{C}$.

\section{Reaction at room temperature using 500 grams of calcium chloride}

Anhydrous ammonia (140.0 g, $8.2 \mathrm{~mol}$ ) was introduced at room temperature in four portions over a period of four days to a well-stirred mixture of reagent grade acetone $(1000 \mathrm{~g}, 17.2 \mathrm{~mol})$ and anhydrous calcium chloride (500 g, 4-20 mesh size). After the final introduction, the reaction mixture was left undisturbed for three days. The crude reaction mixture $(1630 \mathrm{~g})$ was separated into two portions of $815 \mathrm{~g}$ each. One portion was distilled, as described in general procedure $\mathrm{A}$, for recovery of acetone. Thus was obtained $130 \mathrm{~g}(86 \%$ of the acetone determined by gas chromatography, or $38 \%$ of the acetone actually present). The solid residue remaining in the flask was then worked up as described in the general procedure A. Thus was obtained $170 \mathrm{~g}$ of crude 1 of $86 \%$ purity. Distillation of the crude material afforded $140 \mathrm{~g} \quad(31 \%$ yield based on total acetone, or $42 \%$ yield taking into account recovered acetone) of 1, b. p. $50-53^{\circ} \mathrm{C}$ (1 torr), m.p. $34-36{ }^{\circ} \mathrm{C}$. The other portion was poured into a $10{ }^{\circ} \mathrm{C}$ solution of $50 \mathrm{~g}$ of sodium hydroxide in $100 \mathrm{ml}$ distilled water.

The oil was decanted and analyzed by gas chromatography. Unreacted acetone plus that reacted to 1 and all by-products was accountable to $99 \%$. The oil was warmed to $30^{\circ} \mathrm{C}$ at 100 torr to distill off $280 \mathrm{~g}(56 \%$ based on moles initially used) of acetone. The oil remaining was dissolved in $200 \mathrm{ml}$ diethyl ether. The solution was dried over magnesium sulfate and the drying agent was removed by filtration. Removal of the solvent on a rotating evaporator at $23{ }^{\circ} \mathrm{C}(12-15$ torr $)$ gave $170 \mathrm{~g}$ of crude $\mathbf{1}$. The purity of $\mathbf{1}$, as determined by gas chromatography, was $86 \%$. Distillation of this material afforded $133 \mathrm{~g}(30 \%$ yield based on total acetone, or $68 \%$ yield taking into account recovered acetone) of 1 , b. p. $50-56{ }^{\circ} \mathrm{C}$ (1 torr), m.p. $34-36{ }^{\circ} \mathrm{C}$.

\section{Reaction at room temperature using 350 grams of calcium chloride}

Anhydrous ammonia (143.0 g, $8.4 \mathrm{~mol})$ was introduced at room temperature in four portions over a period of four days to a well-stirred mixture of reagent grade acetone $(1000 \mathrm{~g}, 17.3 \mathrm{~mol})$ and anhydrous calcium chloride ( $350 \mathrm{~g}$, 4-8 mesh size). After the final introduction, the reaction mixture was left undisturbed for three days. After the workup, as described in the general procedure B, there was obtained $588 \mathrm{~g}$ of crude $\mathbf{1}$. The purity of this crude material was $69 \%$, as determined by gas chromatography. The acetone, as determined by chromatography plus that converted to 1 and byproducts was accountable to $95 \%$. The crude 1 was of such inferior quality that no crystallization of solid 1 could be achieved from carbon tetrachloride. Distillation of crude 1 afforded $250 \mathrm{~g}$, $(28 \%$ yield based on the starting acetone, or $41 \%$ yield taking into account the acetone as determined by gas chromatography) of 1 , b.p. $50-59^{\circ} \mathrm{C}$ (1 torr), m.p. $33-36{ }^{\circ} \mathrm{C}$. The distillation of the crude material was difficult due to the large amount of impurities present. The major by-product, as determined by gas chromatography, was acetonin (3). This compound comprised $53 \%$ of the impurities.

\section{Reaction at room temperature using 300 grams of calcium chloride}

Anhydrous ammonia (140.0 g, $8.2 \mathrm{~mol}$ ) was introduced at room temperature in three portions over a period of three days to a well-stirred mixture of reagent grade acetone $(1000 \mathrm{~g}, 17.3 \mathrm{~mol})$ and anhydrous calcium chloride ( $300 \mathrm{~g}, 4-8$ mesh size). On the first day, after the first introduction of ammonia (34.0 g, $2.0 \mathrm{~mol})$, a heterogeneous reaction mixture resulted. After $20 \mathrm{~h}$ at room temperature, the reaction mixture became homogeneous. However, it never thickened as had been observed during the optimized reaction (see experiment 1). After the final introduction of ammonia, a heterogeneous mixture resulted once again. Stirring was discontinued, and the reaction mixture was left undisturbed for four days. After the workup as described in the general procedure $\mathbf{B}$, there was obtained $540 \mathrm{~g}$ of crude 1. The purity of 1 , as determined by gas chromatography, was $59 \%$. Acetonin (3) comprised $50 \%$ of the total impurities. Unreacted acetone plus that converted to $\mathbf{1}$ and by-products was accountable to $99 \%$. The crude 1 was of such an inferior quality that no crystallization of solid 1 could be achieved from carbon tetrachloride. The crude reaction mixture was distilled to give $201 \mathrm{~g}(22 \%$ yield based on starting acetone, or $37 \%$ yield based on acetone as determined by gas chromatography) of 1, b. p. $51-59{ }^{\circ} \mathrm{C}$ (1 torr), m.p. $33-36{ }^{\circ} \mathrm{C}$.

\section{Reaction at room temperature using 250 grams of calcium chloride}

Anhydrous ammonia (141.0 g, $8.3 \mathrm{~mol}$ ) was introduced at room temperature in three portions over a period of three days to a well-stirred mixture of reagent grade acetone $(1000 \mathrm{~g}, 17.3 \mathrm{~mol})$ and anhydrous calcium chloride (400 g, 4-8 mesh size). On the first day, a heterogeneous reaction mixture resulted during the first introduction of ammonia $(27.0 \mathrm{~g}, 1.6 \mathrm{~mol})$. After $20 \mathrm{~h}$ at room temperature, the reaction mixture became homogeneous. However, it never thickened, as had been observed during the optimized reaction (see experiment 1), and 
became permanently heterogeneous between the third and fourth days of introduction. Following the final introduction of ammonia, the reaction mixture was left undisturbed for three days. After the workup as described in the general procedure B, there was obtained $515 \mathrm{~g}$ of crude $\mathbf{1}$. The purity of $\mathbf{1}$, as determined by gas chromatography, was $48 \%$. The major impurity comprising $52 \%$ of the byproducts was acetonin (3). Unreacted acetone as determined by gas chromatography plus that converted to 1 and all by-products was accountable to $98 \%$. The crude reaction mixture was of such an inferior quality that no crystallization of solid $\mathbf{1}$ could be achieved from carbon tetrachloride. The crude material was distilled to give $170 \mathrm{~g}$ (19\% yield based on starting acetone, or $34 \%$ yield taking into account the acetone determined by gas chromatography) of 1 , b. p. $51-56{ }^{\circ} \mathrm{C}$ (1 torr), m.p. $35-36{ }^{\circ} \mathrm{C}$.

\section{Reaction at room temperature using 215 grams of calcium chloride}

Anhydrous ammonia (139.0 g, $8.2 \mathrm{~mol}$ ) was introduced at room temperature in four portions during a period of four days to a well-stirred mixture of reagent grade acetone $(1000 \mathrm{~g}, 17.3 \mathrm{~mol})$ and anhydrous calcium chloride ( $215 \mathrm{~g}, 4-8$ mesh size). On the first day, a heterogeneous reaction mixture resulted during the first introduction of ammonia $(22.0 \mathrm{~g}, 1.3 \mathrm{~mol})$. During the course of the four day period of introduction, the reaction mixture occasionally acquired homogeneity. However, it never thickened, as had been observed during the optimized reaction (see experiment 1), and turned heterogeneous during the final introduction of ammonia. Stirring was discontinued, and the reaction mixture was left undisturbed for three days. After the workup as described in the general procedure B, there was obtained $472 \mathrm{~g}$ of crude 1 . The purity of $\mathbf{1}$, as determined by gas chromatography, was $36 \%$. The major impurity, comprising $52 \%$ of the total by-products, was acetonin (3). Unreacted acetone, as determined by gas chromatography, plus that converted to $\mathbf{1}$ and by-products was accountable to $87 \%$. The crude 1 was of such an inferior quality that no crystallization of solid $\mathbf{1}$ could be achieved from carbon tetrachloride. The crude reaction mixture was distilled to give $150 \mathrm{~g}$ ( $17 \%$ yield based on starting acetone, or $31 \%$ yield taking into account the acetone as determined by

1 W. Heintz, Ann. 174, 133 [1874].

2 W. Heintz, Chem. Zbl. 1874, 372.

3 W. Heintz, Berliner Monatsber. 1874, 235.

4 N. Sokoloff and P. Latschinoff, Ber. 7, 1384 [1974].

5 F. Francis, J. Chem. Soc. 1927, 2897.

6 H. HALL, J. Amer. Chem. Soc. 79, 5444 [1957].

7 F. Asinger, A. Saus, and E. Michel, Monatsh. Chem. 99(4), 1436 [1968].

8 E. G. Rozantsev and V. P. Ivanov, Khim-Farm. Zh. 5(1), 47 [1971].

9 K. Murayama, S. Morimura, O. Amakasu, T. Toda, gas chromatography) of 1 , b.p. $51-55{ }^{\circ} \mathrm{C}$ (1 torr), m.p. $34-36^{\circ} \mathrm{C}$. Also obtained was $130 \mathrm{~g}(15 \%$ yield based on starting acetone, or $22 \%$ yield based on acetone as determined by gas chromatography, or $84 \%$ of the amount determined to be present by gas chromatography) of acetonin (3), b. p. 50-59 ${ }^{\circ} \mathrm{C}$ (15 torr). The purity of 3 , as determined by gas chromatography, was $91 \%$.

\section{Reaction at room temperature using 128 grams of calcium chloride}

Anhydrous ammonia (142.0 g, $8.3 \mathrm{~mol}$ ) was introduced at room temperature in five portions over a period of five days to a well-stirred mixture of reagent grade acetone $(1000 \mathrm{~g}, 17.3 \mathrm{~mol})$ and calcium chloride (128 g, 4-8 mesh size). On the first day, a heterogeneous reaction mixture resulted during the first introduction of ammonia $(20.0 \mathrm{~g}$, $1.2 \mathrm{~mol})$. During the course of the five day period of introduction, the reaction mixture never thickened, as had been observed during the optimized reaction (see experiment 1), and frequently changed from a homogeneous state to a heterogeneous state. After the final introduction of ammonia, the reaction mixture was left undisturbed for two days. Following the workup as described in the general procedure $\mathrm{B}$, there was obtained $480 \mathrm{~g}$ of crude 1 . The purity of 1 , as determined by gas chromatography was $35 \%$. The acetone as determined by gas chromatography plus that converted to $\mathbf{1}$ and byproducts was accountable to $88 \%$. The crude 1 was of such an inferior quality that no crystallization of solid 1 could be achieved from carbon tetrachloride. The major by-product, as determined by gas chromatography, was acetonin (3). This compound comprised $59 \%$ of the impurities. The crude reaction mixture was distilled to give $120 \mathrm{~g}(13 \%$ yield based on starting acetone, or $23 \%$ yield taking into account the acetone as determined by gas chromatography) of 1, b.p. $52-56{ }^{\circ} \mathrm{C}$ (1 torr), m.p. $35-36{ }^{\circ} \mathrm{C}$. The additional details of this experiment, including the amount of $\mathbf{1}$ formed each day and the appearance of the reaction mixture follow.

This investigation was supported by grants from the Public Health Service, U.S. Department of Health, Education, and Welfare, GM 16741, and from the Graduate School of the University of Wisconsin-Milwaukee.

and E. Yamao, Nippon Kagaku Zasshi 1969, 90(3), 296.

10 (a) I. B. Simon and V. P. Vvedenskit, Med. Prom. SSSR, No. 5, 9 [1963]; (b) A. Y. Misharin, A. V. Azhaev, and O. L. Poly anovskit, Izv. Akad. Nauk SSSR Ser. Khim. 1975, 1185.

11 I. Guareschi, Atti Acc. Sci. Torino. Classe Sci. Fis., Mat. Nat. 29, 680 [1894].

12 I. Guareschi, Ber. 28, 160 [1895].

13 C. Sandris and G. Ouarisson, Bull. Soc. Chim. Fr. 1958, 345 .

14 B. KaJiyama et al., Ger. Patent 2453174 [1975]. 


\begin{tabular}{|c|c|c|c|c|c|}
\hline Day & $\begin{array}{l}\text { Ammonia introduced } \\
\text { per day } \\
\mathrm{g} \text { [mols }]\end{array}$ & $\begin{array}{l}\text { Total ammonia } \\
\text { in reaction mixture } \\
{[\%]}\end{array}$ & $\begin{array}{l}\text { Duration of } \\
\text { introduction } \\
{[\mathrm{min}]}\end{array}$ & $\begin{array}{l}\text { Temperature } \\
\text { during introduction } \\
{\left[{ }^{\circ} \mathrm{C}\right]}\end{array}$ & $\begin{array}{l}\mathbf{1} \\
\text { Present } \\
{[\%]}\end{array}$ \\
\hline $1^{\mathrm{a}}$ & $20.0(1.2)$ & 14 & 40 & $26-30$ & $0^{f}$ \\
\hline $2^{\mathrm{b}}$ & $35.0(2.1)$ & 39 & 60 & $26-35$ & 2 \\
\hline $3^{c}$ & $37.0(2.2)$ & 65 & 60 & $26-43$ & 7 \\
\hline $4^{\mathrm{d}}$ & $30.0(1.8)$ & 85 & 35 & $25-36$ & 8 \\
\hline $5^{\mathrm{e}}$ & $20.0(1.2)$ & $100(8.3 \mathrm{~mol})$ & 30 & $25-36$ & 9 \\
\hline 6 & & & & & 9 \\
\hline 7 & & & & & 10 \\
\hline 8 & & & & & $13^{\mathrm{g}}$ \\
\hline
\end{tabular}

a The reaction mixture was a heterogeneous system of a white solid and a colorless liquid. After the addition, the mixture turned homogeneous, pale yellow overnight. $\mathrm{b}$ The reaction mixture was a loose, pale yellow uniform suspension. " The mixture became heterogeneous, consisting of an orange liquid and a white solid during the third introduction. ${ }^{d}$ The reaction mixture consisted of a red liquid and a white solid. e A bright orange homogeneous, loose mixture resulted during the final introduction. ${ }^{\mathrm{f}}$ The analyses for $\mathbf{1}$ in the reaction mixture were always performed by gas chromatography approximately $24 \mathrm{~h}$ after the previous day's introduction of ammonia, $i . e$. just prior to the next introduction. $\mathrm{g}$ The yield was based on $\mathbf{1}$ obtained after distillation of the crude product, without taking into account the unreacted acetone, as determined by gas chromatography. The yield was $23 \%$ on taking into account this unreacted acetone.

15 K. Murayama et al., Ger. Patent 2429745 [1975]. 16 E. Matter, Helv. Chim. Acta 30, 1114 [1947].

17 R. B. Bradbury, N. C. Hancox, and H. H. Hatt, J. Chem. Soc. 1947, 1394.

18 E. G. Rozantsev, Free Nitroxyl Radicals, Plenum Press, New York 1970, and references therein.
19 G. Sosnovsky and M. Konieczny, Synthesis 1976, 735 .

20 W. B. Lutz, S. Lazarus, and R. L. Meltzer, J. Org. Chem. 27, 1695 [1962].

21 Org. Syn. Coll. Vol. I, p. 196, John Wiley and Sons, Inc., New York 1932. 